$\begin{array}{ll}\text { Volume } & : 05 \\ \text { Nomor } & : 03 \\ \text { Bulan } & : \text { September } \\ \text { Tahun } & : 2019 \\ \text { http } & : / / \text { ejurnal.pps.ung.ac.id/index.php/AKSARA/index }\end{array}$

\title{
UU BHP DAN TENDENSI LIBERALISASI PENDIDIKAN (Mensintesis Perbaikan Kurikulum \& Kelembagaan)
}

\author{
Yuhelson \\ Dosen Universitas Jayabaya Jakarta \\ yuhelson@gmail.com
}

Received: 02 Juni 2019; Revised: 19 Juli 2019; Accepted: 25 Agustus 2019

\begin{abstract}
ABSTRAK
Terlepas dari pro dan kontra mengenai UU BHP, praktik pendidikan yang terjadi selama ini sehingga benang merah dari kontroversi UU BHP bisa diurai. Sudah bukan rahasia lagi jika pendidikan selama ini hanya menguntungkan kelas berpunya. Kondisi di atas berimbas pada kualitas sumber daya manusia (SDM) kita. Betapa tidak, dari 5,6 juta manusia muda yang berpendidikan SLTA, ternyata hanya 1,6 juta yang bisa mengenyam pendidikan tinggi. Sementara yang lainnya harus rela berijazah SLTA hanya karena terganjal masalah mahalnya biaya pendidikan. Karena itu, tidak perlu menutup muka jika kualitas pendidikan negeri ini merosot dan menempati urutan ke-110 dari 173 negara menurut Human Development Index (HDI). Padahal, UUD 1945 telah mengamanahkan dengan jelas bahwa negara memiliki kewajiban memberikan pendidikan yang layak bagi warga negaranya. Tulisan ini berpretensi pada wilayah pendidikan yang sejatinya merupakan institusi pencerahan lambat laun berubah menjadi lembaga berorientasi pasar. Dalam sebuah pasar, logika yang berlaku adalah meraup keuntungan sebesar-besarnya dengan modal sekecil-kecilnya. Dan, konsumen utama logika tersebut dalam dunia pendidikan tentu saja siswa dan mahasiswa. Ini yang akan kita kembangkan atau lebih popular BHP dibawah bayang-bayang liberalisasi pendidikan
\end{abstract}

Kata kunci: pendidikan, liberalisasi, pasar dan BHP

\section{PENDAHULUAN}

Kesan inilah yang menguat ketika Undang-Undang No 9/2009 tentang Badan Hukum Pendidikan (UU BHP) digelindingkan. Sejatinya undang-undang itu ditujukan untuk memperkuat otonomi penyelenggaraan pendidikan, tetapi dalam ranah publik dimaknai sebagai usaha lepas tangan pemerintah sehingga menjadi kontroversi yang berkelanjutan. Pada jenjang pendidikan dasar dan menengah, UU tersebut merupakan kelanjutan dari manajemen berbasis sekolah/madrasah (school based management) yang merupakan bentuk otonomi manajemen pendidikan pada satuan pendidikan. Sementara itu, pada jenjang perguruan tinggi, UU tersebut menjadi landasan otonomi perguruan tinggi yang merupakan kemandirian perguruan tinggi untuk mengelola sendiri lembaganya.

Dalam upaya memfasilitasi pengaturan pengelolaan pendidikan, termasuk pendidikan tinggi sebagaimana tersurat dalam UU No 20/2003 tentang Sistem Pendidikan Nasional Pasal 53 ayat (1) dan (2), di penghujung 2008 pemerintah bersama DPR menetapkan UU No 9/2009 tentang Badan Hukum Pendidikan (BHP) yang secara bertahap menuntut konvergensi pengelolaan perguruan tinggi. Kehadiran UU BHP sejatinya bisa menjadi instrumen untuk 


$\begin{array}{ll}\text { Volume } & : 05 \\ \text { Nomor } & : 03 \\ \text { Bulan } & : \text { September } \\ \text { Tahun } & : 2019 \\ \text { http } & : / / \text { ejurnal.pps.ung.ac.id/index.php/AKSARA/index }\end{array}$

memperkuat otonomi PT sehingga kemandirian pengelolaan PT benar-benar dilaksanakan secara transparan dan akuntabel. Pengelolaan PT yang transparan dan akuntabel akan mampu memperkuat kepercayaan (trust) stakeholder terhadap PT sehingga civitas academica dapat fokus memperkuat kualitas layanannya secara otonom.

\section{TINJAUAN PUSTAKA}

\section{Membedah Benang Merah}

UUD 1945 telah mengamanahkan dengan jelas bahwa negara memiliki kewajiban memberikan pendidikan yang layak bagi warga negaranya. Namun demikian, paling tidak hal yang harus diperhatikan adalah. Pertama, pendidikan saat ini telah berada di bawah kangkangan modal. Indonesia yang kini menganut sistem ekonomi liberal terpaksa menempatkan negara sebagai penjamin bagi keberlangsungan sistem ekonomi pasar. Terobosan ini memang bermula dari pencopotan semua layanan publik dari negara, namun lama-kelamaan menjadi upaya melakukan kapitalisasi semua bentuk layanan publik. Termasuk juga di dalamnya lembaga pendidika (Eko Prasetyo, 2009: 32).

Pendidikan yang sejatinya merupakan institusi pencerahan lambat laun berubah menjadi lembaga berorientasi pasar. Dalam sebuah pasar, logika yang berlaku adalah meraup keuntungan sebesar-besarnya dengan modal sekecil-kecilnya. Dan, konsumen utama logika tersebut dalam dunia pendidikan tentu saja siswa dan mahasiswa. Setidaknya ada dua jalur bagaimana logika pasar itu bergerak dalam pendidikan.

Jalur pertama, intervensi materi (baik pelajaran maupun sistem pengajaran yang cocok bagi kepentingan dan kelancaran produksi). Jalur kedua, menyuplai segala kebutuhan sekolah, mulai dari buku, seragam hingga kurikulum. Dengan kata lain, sekolah tak ubahnya pasar swalayan.

Kedua, pendidikan dengan politik. Politik tersebut didesakkan dalam dunia pendidikan untuk mempertahankan status quo penguasa. Sebenarnya dengan menelurkan UU BHP, pemerintah sadar bahwa biaya pendidikan akan melambung tinggi dan yang akan terhempas tentu saja masyarakat miskin. Tapi, hanya dengan cara itulah penguasa bisa terus mempertahankan politik massa mengambang (floating mass). Menjauhkan masyarakat dominan dari gerbang pendidikan agar mudah memanipulasi kesadaran mereka.

Tujuannya apa lagi kalau bukan untuk kepentingan politik. Misalnya saja saat pemilu berlangsung. Dengan massa mengambang, penguasa dan elite politik bisa dengan mudah meraup massa banyak dengan menggunakan beragam cara, mulai politik kotor hingga money politic tanpa mendapat kritik dari masyarakat. Di samping itu, politik massa mengambang, menurut Habermas, juga berfungsi sebagai kontrol, pengawasan terhadap gerak-gerik masyarakat. Dengan demikian, meminjam istilah Pramoedya Ananta Toer, masyarakat ibarat berada dalam rumah kaca.

Benar memang pemerintah memiliki program "mulia" terkait dengan pendidikan. Misalnya, gerakan nasional orang tua asuh (GNOTA), wajib belajar 9 tahun, dan masyarakat bebas buta aksara. Tapi, dalam realitasnya, program tersebut tak pernah berhasil optimal. Bukan karena masyarakat miskin tak mau mengenyam pendidikan, melainkan karena program yang dijalankan tidak tepat sasaran dan tidak menyesuaikan dengan kultur setempat. Akibatnya, yang terjadi, masyarakat tetap berkubang dalam kemiskinan dan kebutaan pengetahuan. Parahnya lagi, kondisi ini justru dimanfaatkan negara dan kaum kapital untuk lagi-lagi meraup keuntungan dengan menggiring massa menjadi buruh murah. Ini sungguh 


$\begin{array}{ll}\text { Volume } & : 05 \\ \text { Nomor } & : 03 \\ \text { Bulan } & : \text { September } \\ \text { Tahun } & : 2019 \\ \text { http } & : / / \text { ejurnal.pps.ung.ac.id/index.php/AKSARA/index }\end{array}$

sebuah ironi. Padahal, di tengah krisis saat ini, masyarakat membutuhkan pendidikan dalam arti sejati. Dalam hal ini mereka perlu mendapatkan pengetahuan dan wawasan untuk terus mengembangkan diri dan menggali potensi sehingga dapat bangkit dari krisis. Dengan pendidikan yang demikian, rakyat tak lagi menjadi objek yang gampang ditindas dan dibodohi.

\section{Pendidikan Tinggi di Era Perdagangan Bebas}

Sungguh tepat untuk dibicarakan oleh masyarakat pendidikan yang hari ini sedang memperingati Hari Pendidikan Nasional (Hardiknas). Bentuk dan rona pendidikan tinggi di Era Perdagangan Bebas semakin perlu kita fahami karena pada akhir bulan Mei 2005 negaranegara anggota WTO akan menandatangani General Agreement on Trade in Services (GATS) yang mengatur liberalisasi perdagangan 12 sektor jasa, antara lain layanan kesehatan, teknologi informasi dan komunikasi, jasa akuntansi, pendidikan tinggi dan pendidikan selama hayat, serta jasa-jasa lainnya.

Dalam tipologi yang digunakan oleh para ekonom kegiatan usaha dalam masyarakat dibagi dalam 3 sektor. Sektor primer mencakup semua industri ekstraksi hasil pertambangan dan pertanian. Sektor sekunder mencakup industri untuk mengolah bahan dasar menjadi barang, bangunan, produk manufaktur dan utilities. Sektor tersier mencakup industri-industri untuk mengubah wujud benda fisik (physical services), keadaan manusia (human services) dan benda simbolik (information and communication services). Sejalan dengan pandangan ilmu ekonomi, WTO menetapkan pendidikan sebagai salah satu industri sector tersier, karena kegiatan pokoknya adalah mentransformasi orang yang tidak berpengetahuan dan orang tidak punya ketrampilan menjadi orang berpengetahuan dan orang yang punya ketrampilan. Kontribusi sektor tersier terhadap produk nasional suatu bangsa memang cenderung meningkat seiring dengan kemajuan pembangunan bangsa tersebut. Sejak 1980-an di negaranegara maju, perdagangan jasa tumbuh pesat dan telah memberikan sumbangan yang besar pada produk domestik bruto (PDB), lebih besar dibandingkan dengan sector primer dan sekunder. Tiga negara yang paling mendapaatkan keuntungan besar dari liberalisasi jasa pendidikan adalah Amerika Serikat, Inggeris dan Australia (Enders dan Fulton, Eds., 2002, hh 104-105). Pada 2000 ekspor jasa pendidikan Amerika mencapai US \$ 14 milyar atau Rp. 126 trilyun. Di Inggeris sumbangan pendapatan dari ekspor jasa pendidikan mencapai sekitar 4 persen dari peneimaan sector jasa Negara tersebut. Menurut Millea (1998), sebuah publikasi rahasia berjudul Intelligent Exports mengungkapkan bahwa pada 1994 sector jasa telah menyumbangkan 70 persen pada PDB Australia, menyerap 80 persen tenaga kerja dan merupakan 20 persen dari ekpor total negara Kangguru tersebut, Sebuah survey yang diadakan pada 1993 menunjukkan bahwa industri jasa yang paling menonjol orientasi ekpornya adalah jasa komputasi, pendidikan dan pelatihan. Ekpor jasa pendidikan dan pelatihan tersebut telah menghasilkan AUS \$ 1,2 milyar pada 1993. Fakta tersebut dapat menjelaskan mengapa tiga negara maju tersebut amat getol menuntut liberalisasi sector jasa pendidikan melalui WTO, Sejak 1995 Indonesia telah menjadi anggota WTO dengan diratifikasinya semua perjanjian-perjanjian perdagangan multilateral menjadi UU No, 7 tahun 1994. Perjanjian tersebut mengatur tata-perdagangan barang, jasa dan trade related intellectual property rights (TRIPS) atau hak atas kepemilikan intelektual yang terkait dengan perdagangan.

\section{Internasionalisasi dan Globalisasi}

Internasionalisasi dan globalisasi adalah ibarat kembar siam yang hampir sama bentuk 


$\begin{array}{ll}\text { Volume } & : 05 \\ \text { Nomor } & : 03 \\ \text { Bulan } & : \text { September } \\ \text { Tahun } & : 2019 \\ \text { http } & : \text { //ejurnal.pps.ung.ac.id/index.php/AKSARA/index }\end{array}$

fisiknya tetapi berbeda sifat dan wataknya. Atau dapat juga ditamsilkan sebagai orang yang memiliki kepribadian ganda. Yang pertama adalah kepribadian yang baik, sopan, dan santun. Yang kedua, adalah kepribadian yang jahat, brutal dan gragas alias tamak. Dunia pendidikan, khususnya pendidikan tinggi, telah lama, atau bahkan sejak awal kelahirannya telah berkenalan baik dengan internasionalisasi, kalau tidak mau mengatakan bahwa pendidikan tinggi adalah buah dari internasionalisasi ilmu pengetahuan, seni dan budaya. Karena menyadari manfaat besar dan positif dari internasionalisasi, hampir tidak ada negara yang secara sadar mau memisahkan dirinya dari arus internasionalisasi. Bahkan dalam Pembukaan UUD 1945 tercantum jelas bahwa salah satu tujuan pendirian Repbulik Indonesia amat dijiwai oleh semangat internasionlisme yaitu "ikut melaksanakan ketertiban dunia yang berdasarkan kemerdekaan, perdamaian abadi dan keadilan sosia "Globalisasi, menurut Stiglitz (2003), merupakan interdependensi yang tidak simetris antar negara, lembaga dan aktornya.

\section{Pengaruh Perdagangan Bebas terhadap Pendidikan Tinggi}

Perdagangan bebas jasa yang dipraktekkan dalam globalisasi berwatak fundamentalisme pasar akan mempunyai dampak yang amat besar pada lembaga dan kebijakan pendidikan tinggi. Dampak tersebut amat bervariasi tergantung dari lokasinya di arena global, dapat membuka peluang atau menguntungkan tetapi dapat juga merupakan hambatan atau merugikan sektor pendidikan negara berkembang. Perdagangan bebas jasa pendidikan tinggi kalau dilaksanakan dalam kondisi interdependensi simetris antar negara atau lembaga pendidikan memang dapat membuka lebar pintu menuju ke pasar kerja global khususnya ke ekonomi negara maju yang telah mampu mengembagkan ekonomi berbasis ilmu pengetahuan (knowledge based economy). Tapi dalam kondisi interdependensi asimetris dan lebih-lebih bila penyediaan jasa pendidikan tinggi lebih dilandasi oleh motif for-profit semata, sedangkan tujuan- tujuan pendidikan lainnya akan dikorbankan. WTO telah mengidentifikasi 4 mode penyediaan jasa pendidikan sebagai berikut: (1) Cross-border supply, institusi pendidikan tinggi luar negeri menawarkan kuliah- kuliah melalui internet dan on-line degree program, atau Mode 1; (2) Consumption abroad, adalah bentuk penyediaan jasa pendidikan tinggi yang paling dominan, mahasiswa belajar di perguruan tinggi luar negeri atau Mode 2; (3) Commercial presence, atau kehadiran perguruan tinggi luar negeri dengan membentuk partnership, subsidiary, twinning arrangement dengan perguruan tinggi lokal., atau Mode 3, dan (4) Presence of natural persons, dosen atau pengajar asing mengajar pada lembaga pendidikan lokan, atau Mode 4. Liberalisasi pendidikan tinggi menuju perdagangan bebas jasa yang dipromosikan oleh WTO adalah untuk mendorong agar pemerintah negara- negara anggota tidak menghambat empat mode penyediaan jasa tersebut dengan kebijakan-kebijakan intervensionis. Dibandingkan dengan negara-negara anggota Asean yang tergabung dalam Asean University Network (AUN) ataupun (Association of Southeast Asia Institute of Higher Learning (ASAIHL), seperti Malaysia, Muangthai, Filipina dan Singapore, Indonesia jauh tertinggal dalam tingkat partisipasi pendidikan tinggi dan mutu akademik. Pada tahun 2004 tingkat partisipasi pendidikan tinggi baru mencapai 14 persen, jauh tertinggal dari Malaysia dan Filipina yang sudah mencapai 38-40 persen. Karena kemampuan keuangan pemerintah yang sangat terbatas, ekspansi serta peningkatan mutu pendidikan tinggi Indonesia tidak mungkin dilakukan dengan mengandalkan sumber dana domestik. Ekspansi pendidikan tinggi dan peningkatan mutu akademik nampaknmya hanya mungkn dilakukan bila layanan pendidikan tinggi oleh provider luar negeri yang dimungkinkan oleh globalisasi pendidikan dapat dimanfaatkan oleh negara berkembang seperti Indonesia. 


$\begin{array}{ll}\text { Volume } & : 05 \\ \text { Nomor } & : 03 \\ \text { Bulan } & : \text { September } \\ \text { Tahun } & : 2019 \\ \text { http } & : \text { //ejurnal.pps.ung.ac.id/index.php/AKSARA/index }\end{array}$

\section{Strategi Menghadapi Liberalisasi Pendidikan}

Globalisasi atau liberalisasi pendidikan tinggi yang sedang terjadi melalui jalur pasar bebas memang harus dihadapi dengan sangat hati-hati oleh negara-negara berkembang, tak terkecuali Indonesia. Implikasi jangka panjang dari globalisasi pendidikan tinggi tersebut belum sepenuhnya dapat di prakirakan, dan karena itu kewbijakan-kebijakan antisipatif perlu dirancang dengan secermat mungkin agar globalsasi tersebut jangan sampai menghancurkan sektor pendidikan tinggi seperti yang terjadi dengan globalisasi sektor pertanian. Agar dampak seperti itu tidak terjadi, Negara berkembang perlu merumuskan strategi yang paling tepat sebagai berikut: Meskipun konstelasi kekuasaan global yang ada saat ini tidak memungkinkan perguruan tinggi Indonesia, seperti halnya dengan banyak universitas di negara-negara lain, untuk merumuskan dan melaksanakan kebijakan-kebijakan yang kuat untuk menggoyahkan arsitektur kekuasaan global di bawah monopoli GATT/WTO, namun dalam perspektif jangka panjang melalui pengembangan forum dan jaringan kerjasama regional dan internasional memiliki ruang yang cukup lebar untuk menghasilkan perubahanperubahan yang berarti. Reaksi masyarakat pendidikan tinggi terhadap masuknya pendidikan dalam GATS cukup luas. Assosiasiasi Perguruan Tinggi Aemrika dan Kanada, Asosiasi Rektor Uni Eropah, Persatuan Naib Kanselor India, Majelis Rektor dan Perguruan Tinggi Indonesia secara terbuka telah menyampaikan himbauan kepada pemerintah masing-masing untuk meninjau pemberlakuan pendidikan tinggi sebagai komoditi yang diatur melalui GATS. Forum Rektor Indonesia yang mewakili 2300 perguruan tinggi dan lembaga swadaya masyarakat telah menginisiasi kerjasama antara

\section{PENUTUP}

Kiranya amat tepat bila pada peringatan Hari Pendidikan Nasional ini kita menghimbau kepada Pemerintah untuk melaksanakan UU No. 7 Tahu 1994 tentang ratifikasi perjanjian WTO dan perjanjian-perjanjian multilateral, tetapi dengan amat memerhatikan kepentingan dan tujuan nasional bahwa salah satu tujuan kemerdekaan adalah mencerdaskan kehidupan bangsa. Dengan demikian tugas pendidikan tinggi bukan semata-mata menghasilkan tenaga kerja terdidik, atau pengertian jasa sebagai indistri tersier dalam konsep para ekonom, tetapi dia juga adalah lembaga untuk "to preserve national identity", "to sustain and develop the intellectuial and cultural base of the society", "to give inspiration and pride to citizens", dan "to promote dialoge for the respect of cultural and social diversity". Tujuan-tujuan nasional yang penting tetap menjadi tanggung-jawab bangsa Indonesia karena tidak mungkin mendapat perhatian sepenuhnya dari penyedia jasa pendidikan komersial luar negeri.

Untuk itu pelaksanaan liberalisasi jasa pendidikan tinggi dan sub-sektor pendidikan lainnya haruslah dilakukan dengan secara bertahap dan dengan memperhitungkan kesiapan nasional kita untuk mengembangkan hubungan yang simetris dengan lembaga pendidikan tinggi negara lain. Tanpa kesiapan nasional tersebut, dikhawatirkan sector pendidikan kita akan menjadi korban dari habungan assimetris atauy persaingan yang tidak seimbang dengan penyedia layanan pendidikan dari Negara lain. Karena itu adalah sangat bijaksana kalau Pemerintah Indonesia tidak terlalu terburu-buru membuka sector jasa pendidikan tinggi dan menawarkan sector tersebut sebagai pasar subur untuk dilahap oleh negara-negara maju. Jangan masukkan sector pendidikan tinggi pada GATS yang akan ditandatangi pada bulan Mei 2005. 


$\begin{array}{ll}\text { Volume } & : 05 \\ \text { Nomor } & : 03 \\ \text { Bulan } & : \text { September } \\ \text { Tahun } & : 2019 \\ \text { http } & : \text { //ejurnal.pps.ung.ac.id/index.php/AKSARA/index }\end{array}$

\section{DAFTAR PUSTAKA}

ASEAN Secretariat. ASEAN framework agreement on services. Jakarta. Asean Secreatriat. 1995.

De Groof, Jan, Gracienne Lauvers, dan Germain Dondelinger. Globalization and Comptetion in Education. Nijmegen, The Netherlands. Wolf Legal Publishers. 2003.

Departemen Pendidikan Nasional. Rencana Strategis 2004-2009. Jakarta. Depdiknas, 2005.

Enders, Jurgen dan Oliver Fulton. Eds., Higher Education in a Globalizing World. Dordrecht. Kluwer Academic Publishers. 2002.

ILO. "Life-long learning in the Twenty-first Century: The changing role of educational personnel". Report for the discussion at the Joint Meeting on Lifelong Learning in the Twenty-first Century. (www.ilo.org/public/english/dialogue).

Mallea, J. Interantional trade in professional and educational services: implications for The profession and higher education. Paris. OECD-CERI.

(http://www.oecd.org/els/papers/papers.htm).

Peace Lenn, M. "The globalization of the professions and higher education: trade agreements, new technologies and the quality imperative." Higher Education in Europe, 21 (4) 89-96.

Mallea, John R. International Trade in Professional and Educational Services. Paris. OECD, Centre for Educational Research and Innovation. 1998

Milles, M. "Services: The Intyerdependent Economy". Paper presented at Japanese Service Investment in Europe, Programme of Policy Research in Engineering, Science and Technology, University of Manchester. April 1995.

OECD. International trade in professional services: Advancing liberalization through regulatory reform. Paris. OECD. 1997.

Rektor UGM. Revitalisasi jati diri Universitas Gadjah Mada menghadapi perubahan global. Pidato Dies ke 55. Yogyakarta. Universitas Gadjah Mada. 20 Desember 2004.

Robertson, Robbie. 2003. The Three Waves of Globalization: A History of a Developing Global Consciousness, London dan New York: Zed Books

Scott, P., Ed. The globalization of higher education. Buckingham. OUP \& SHRE, 1998. Smiers, Joost. 2003. Arts under Pressure: Protecting Cultural Diversity in Age of Globalization. London and New York, NY: Zed Books.

Stiglitz, Joseph E. Globalization and Its Discontents. New York. W.W. Norton\& Co. 2003

Tehranian, Majid. 1999. Global Communication and World Politics: Domination, Development, and Discourse, Linne Rienner Publishers.

Warouw, Adolf. "Liberalisasi jasa pendidikan dalam kerangka WTO”. Presentasi pada Diskusi Liberalisasi Jasa Pendidikan. Diselenggarakan oleh Departemen Perdagangan. Jakarta, Webster, Frank, 2002, Theories of the Information Society. New York, NY: Routledge. Van Glinken, Hans, "Globalization, Higher Education and Sustainable Development". Paper at First Asean - European Union Rectors' Conference. Organized by Ministry of Higher Education of Malaysia, University of Malaya, Delegation of the European Commission in Malaysia, and Asean - European Union Network

Programme. Kuala Lumpur, October 4-6, 2004 